\title{
RESÍDUOS SÓLIDOS URBANOS: ESTUDO DE CASO DA ESTÂNCIA TURÍSTICA DE TUPÃ/SP
}

\author{
Sandra Medina Benini ${ }^{1}$
}

Encarnita Salas Martin ${ }^{2}$

\begin{abstract}
RESUMO: Este artigo tem por objetivo realizar uma breve análise sobre a gestão dos resíduos sólidos urbanos da Estância Turística de Tupã/SP. Para o desenvolvimento deste trabalho foi feito: a conceituação dos tipos de resíduos sólidos; a caracterização do sítio urbano e a identificação dos depósitos tecnogênicos; e por fim, um realizado um breve inventário sobre a gestão dos resíduos sólidos urbanos no município, considerando a coleta, tratamento e destinação final. Como procedimento metodológico adotou-se uma pesquisa qualitativa relacionada à temática proposta, a partir do exame da literatura pertinente a estudos científicos (livros, teses, dissertações, artigos, legislação etc.), bem como, a verificação em loco da disposição dos resíduos sólidos urbanos.
\end{abstract}

Palavras chave: Gestão. Resíduos Sólidos Urbanos. Depósitos Tecnogênicos.

\footnotetext{
${ }^{1}$ Doutoranda no Programa de Pós-Graduação em Geografia UNESP - Universidade Estadual Paulista, Presidente Prudente e Doutoranda no Programa de Pós-Graduação em Arquitetura e Urbanismo da Universidade Presbiteriana Mackenzie. E-mail: sandra@sigmaambiente.com

${ }^{2}$ Professora da Faculdade de Ciências e Tecnologia da UNESP - Campus de Presidente Prudente. E-mail: encarnita@fct.unesp.br
} 


\title{
1 RESÍDUOS SÓLIDOS
}

Com revolução industrial no século XVIII, as cidades se transformaram intensamente. A economia que até então era baseada na produção artesanal foi substituída pela produção industrial, incidindo na ascensão do capitalismo.

Devido à rápida industrialização, houve uma grande demanda de mão de obra, a qual migrou do campo para a cidade, promovendo no adensamento populacional ${ }^{3}$ das cidades. Esses centros urbanos tiveram sua malha urbana esgarçada e conseqüentemente, os problemas urbanos se multiplicaram, principalmente nos bairros pobres, gerando vários conflitos sociais, muitos de ordem urbanística decorrentes da

[...] falta de coleta de lixo, de rede de água e esgoto, as ruas estreitas para a circulação, a poluição de toda ordem, moradias apertadas, falta de espaço para o lazer, enfim, insalubridade e feiúra (SPOSITO, 2004, p.58).

Após a segunda guerra mundial, o modo de vida americano foi adotado pelos demais países capitalistas, que estimulava um consumo excessivo, intensificando o processo industrialização. Entretanto, com uma tecnologia limitada para a época, esses centros industriais emitiam uma grande carga poluidora no ambiente, temos como exemplo: a tragédia de 1952 ocorrida em Londres, com surgimento do fenômeno smog ${ }^{4}$.

Na década de 70, Hobsbawm (1995 apud CALDERONI, 2003) já previa uma "crise ecológica", como afirma:

\begin{abstract}
Uma taxa de crescimento econômico como a da segunda metade do Breve Século $X X$, se mantida indefinidamente [...], deve ter conseqüências irreversíveis e catastróficas para o meio ambiente natural deste planeta, incluindo a raça humana que é parte dele [...] certamente mudará o padrão de vida na biosfera, e pode muito bem torná-la inabitável pela espécie humana... Além disso, o ritmo em que a modernidade tecnologia aumentou a capacidade de nossa espécie de transformar o ambiente é tal que, mesmo supondo que não vá acelerar-se, o tempo disponível para tratar d problema deve ser medido mais em décadas que em séculos. (HOBSBAWM, 1995, p. 575 apud CALDERONI, 2003, p. 31)
\end{abstract}

\footnotetext{
${ }^{3}$ Segundo HARDUEL (1990, p.101) "A população mundial quadruplica após 1850, a população urbana se multiplica por dez".

${ }^{4}$ Smog é [...] uma nuvem gigantesca formada pela poluição industrial onde "4.000 pessoas morreram em poucos dias devido ao aumento na concentração desses poluentes, que se acumularam aprisionados em uma massa de ar que permaneceu estagnada em virtude de uma inversão térmica nas proximidades do solo." Disponível em< http://cave.cave.com.br/fio/smog/smog.htm $>$ Acesso 25.05.2008.
} 
Essas transformações do ambiente provocaram a preocupação da acadêmica, dos chefes de Estados, bem como de uma parcela da população, incidindo em uma mobilização de escala global. O Brasil em 1992, na cidade do Rio Janeiro, sediou a II Conferência das Nações Unidas para o Meio Ambiente e Desenvolvimento - CNUMAD, a questão ecológica foi objeto de debate público mundial, reflexo de uma consciência ambiental que germinava.

$O$ documento da Agenda $21^{5}$ que foi elaborado durante o evento, demonstrou a preocupação dos participantes com a questão dos resíduos sólidos, como uma preocupação da eminente "crise ecológica" (HOBSBAWM, 1995).

Aproximação 5,2 milhões - incluindo 4 milhões de crianças - morrem por ano de doenças relacionadas com o lixo. Metade da população urbana nos países em desenvolvimento não tem serviços de despejo de lixo sólido. Globalmente, o volume de lixo municipal produzido deve dobrar até o final do século e dobrar novamente antes do ano de 2025. (Agenda 21, 1992, p.29)

A Agenda 21 demonstrou um dos grandes dilemas das cidades brasileiras, entre eles, o aumento da geração dos resíduos sólidos ${ }^{6}$, resultado do modelo consumo adotado nos países capitalista. Os organizadores da Agenda 21, diante da importância do problema, reservaram a seção II, capítulo 20/21, os temas "Manejo de Resíduos Perigosos e A Busca de Soluções para o Problema dos Resíduos Sólidos", como propostas de ações nas áreas de "minimização dos resíduos, reutilização e reciclagem e tratamento e disposição ecologicamente racional dos resíduos".

$\mathrm{Na}$ esfera nacional, não há como ignorar a questão, pois cada brasileiro gera, em média, "500 g de lixo por dia, o que equivale a 100.000 t por dia de lixo gerado por dia" e que "segundo dados do IBGE, $80 \%$ das disposições de final do lixo brasileiro é feita em vazadouros a céu aberto" (CRIPPI, 2001). Esses números são motivados pelo consumo acelerado, o que ocasiona demanda cada vez maior por recursos naturas.

\footnotetext{
${ }^{5}$ A Agenda 21 "é um programa de ação, baseado num documento de 40 capítulos, que constitui a mais ousada e abrangente tentativa já realizada de promover, em escala planetária, um novo padrão de desenvolvimento, conciliando métodos de proteção ambiental, justiça social e eficiência econômica." Disponível em < http://www.ecolnews.com.br/agenda21/index.htm> Acesso em 28.05.2008.

${ }^{6}$ Segundo CINCOTTO (1988), "a denominação de resíduo é circunstancial referindo-se a um material acumulado, sem destinação; a partir do momento em que apresente uma aplicação qualificada passa a ser um subproduto".
} 
$\mathrm{Na}$ outra vertente desse contexto, refere-se à falta de local adequado para os resíduos sólidos, o que causa impactos negativos sobre o homem e ao meio ambiente. $\mathrm{O}$ depósito inadequado dos resíduos sólidos favorece a proliferação de vetores responsáveis por diversas doenças (QUADRO 01).

\section{QUADRO 01 - Enfermidades Relacionadas com os Resíduos Sólidos, Transmitidos por Macro Vetores}

\begin{tabular}{|c|c|c|}
\hline VETORES & FORMA DE TRANSMISSÃO & ENFERMIDADES \\
\hline $\begin{array}{l}\text { Ratos e } \\
\text { Pulgas }\end{array}$ & $\begin{array}{l}\text { Mordida, urina, fezes e } \\
\text { picada }\end{array}$ & Leptospirose, Peste Bubônica, Tifo Murino \\
\hline Mosca & $\begin{array}{l}\text { Asas, patas, corpo, fezes e } \\
\text { saliva }\end{array}$ & $\begin{array}{c}\text { Febre Tifóide, Cólera, Amebíase, Disenteria, } \\
\text { Giardíase, Ascaridíase }\end{array}$ \\
\hline Mosquito & Picada & $\begin{array}{l}\text { Malária, Febre Amarela, Dengue, } \\
\text { Leishmaniose, Febre Tifóide, Cólera }\end{array}$ \\
\hline Barata & Asas, patas, corpo e fezes & Giardíase \\
\hline Gado e Porco & $\begin{array}{l}\text { Ingestão de carne } \\
\text { contaminada }\end{array}$ & Teníase, Cistiscercose \\
\hline Cão e Gato & Urina e Fezes & Toxoplamose \\
\hline
\end{tabular}

Fonte: Adaptado de BAKROS apud LIMA, 2001.

Agravando esse panorama caótico, milhares de brasileiros trabalham de forma insalubre, como é o caso dos coletores de resíduos sólidos, nos lixões a céu aberto, juntos com animais e sujeitos as várias doenças infectas contagiosas, homens, mulheres e crianças recolhem materiais para a reciclagem.

Segundo o IBGE - PNSB (2008), a coleta de lixo é amplamente difundida, porém a grande maioria dos municípios (63,3\%) deposita seus resíduos em lixões a céu aberto e sem nenhum tratamento. Os aterros sanitários estão presentes em apenas 13,8\% dos municípios brasileiros, e apenas $8 \%$ deles afirmam ter coleta seletiva ${ }^{7}$.

A Associação Brasileira de Normas Técnicas (ABNT), por meio da Norma Brasileira Registrada (NBR) 10.004 de 2004, define resíduos sólidos como os "resíduos sólidos são resíduos nos estados sólidos e semi-sólidos, que resultam de atividades da comunidade de origem: industrial, doméstica, hospitalar, comercial, agrícola, de serviços e de varrição".

\footnotetext{
${ }^{7}$ Disponível em <http://www.mananciais.org.br/2011/09/saneamento-no-brasil/> Acesso 18.12.2011.
} 
Segundo Grippi (2001), os resíduos sólidos devem ser classificados segundo sua origem e especificações, com objetivo de aferir a responsabilidade do gerenciamento (QUADRO 02).

QUADRO 02 - Classificação, especificação e responsabilidade dos resíduos sólidos.

\begin{tabular}{|c|c|c|}
\hline $\begin{array}{l}\text { CLASSIFICACCÃO } \\
\text { QUANTO Ã } \\
\text { ORIGEM }\end{array}$ & ESPECIFICAÇÕES DOS RESÍDUOS SÓLIDOS & $\begin{array}{l}\text { RESPONSABILIDADE } \\
\text { DE GERENCIAMENTO }\end{array}$ \\
\hline Domiciliar & $\begin{array}{l}\text { É todo aquele produzido pela população no âmbito de sua } \\
\text { residência, sendo constituídos por restos de alimentos, } \\
\text { produtos deteriorados, jornais, revistas, garrafas e } \\
\text { embalagens, papel higiênico e fraldas descartáveis, etc. }\end{array}$ & Prefeitura Municipal \\
\hline Comercial & $\begin{array}{l}\text { E aquele originário de atividade comercial e prestação de } \\
\text { serviços, compreendido em sua maior parte por papel, } \\
\text { plásticos, embalagens, material de asseio (papel toalha, } \\
\text { papel higiênico, etc.) }\end{array}$ & Prefeitura Municipal \\
\hline Público & $\begin{array}{l}\text { É aquele derivado da execução de serviços de limpeza } \\
\text { pública urbana (vias públicas, galerias, córregos, terrenos } \\
\text { baldios, poda de árvores, feiras livres, etc.) }\end{array}$ & Prefeitura Municipal \\
\hline Hospitalar & $\begin{array}{l}\text { É aquele constituído de resíduo séptico que contêm ou } \\
\text { potencialmente podem conter germes patogênicos. São } \\
\text { derivados da prestação de serviços de saúde, seja de } \\
\text { hospitais, clínicas, laboratórios, farmácia, clinicas } \\
\text { veterinárias, postos de saúdes, etc. A composição desse } \\
\text { resíduo é de agulhas, seringas, gazes, bandagens, } \\
\text { algodões e tecidos removidos, meios de culturas, animais } \\
\text { usados em teste, sangue coagulado, remédio, luvas } \\
\text { descartáveis, filmes radiológicos, etc. }\end{array}$ & Gerador \\
\hline Especial & $\begin{array}{l}\text { Este, em especial, é todo aquele encontrado em portos, } \\
\text { aeroportos, terminais rodoviários. É constituído de } \\
\text { resíduos sépticos, podem conter agentes patogênicos } \\
\text { oriundos de um quadro de endemia de outro lugar, } \\
\text { cidade, estado ou país. }\end{array}$ & Gerador \\
\hline Industrial & $\begin{array}{l}\text { Este é originário das atividades industriais, onde os } \\
\text { rejeitos variam conforme a variedade do produto final da } \\
\text { atividade industrial. }\end{array}$ & Gerador \\
\hline agrícola & $\begin{array}{l}\text { São rejeitos das atividades agrícolas e da pecuária, por } \\
\text { exemplo, embalagens de adubos e agrotóxicos, } \\
\text { defensivos agrícolas, ração, restos de colheitas, etc. }\end{array}$ & Gerador \\
\hline
\end{tabular}

Fonte: CRIPP, 2001

Organização: Sandra Medina Benini 2011

Conforme demonstra a tabela, alguns resíduos têm características específicas, como por exemplo, os resíduos sólidos dos serviços de saúde ${ }^{8}$, que têm aspectos

${ }^{8}$ Conforme a Organização Mundial de Saúde - OMS, os resíduos de serviço de saúde são definidos como: Resíduo de serviço de saúde é todo aquele gerado por prestadores de assistência médica, odontológica, laboratorial, farmacêutica, instituição de ensino, relacionados à população humana, bem como veterinários, 
referentes à geração, segregação, acondicionamento, coleta, armazenamento, transporte, tratamento e destinação final, bem como a proteção à saúde pública.

Segundo Philippi Jr. (2005, p. 268-269), “a produção de resíduos sólidos faz parte do cotidiano do ser humano" e é uma questão de "saúde pública". Alguns municípios brasileiros apresentam verdadeiras mazelas ambientais com relação à coleta, manejo e destinação final dos seus resíduos sólidos urbanos.

A questão dos resíduos sólidos merece necessária atenção, uma vez que envolve questões do interesse coletivo, profundamente influenciado por interesses econômicos, sociais, culturais, gerando em alguns casos, conflitos políticos. (PHILIPPI JR., 2005).

$\mathrm{Na}$ geomorfologia, os depósitos de resíduos sólidos são tratados como depósitos tecnogênicos ${ }^{9}$, uma vez que são oriundos da ação antrópica num determinado ambiente e podem ser classificados como:

1- Materiais "úrbicos" (do inglês urbic): tratam-se de detritos urbanos, materiais terrosos que contêm artefatos manufaturados pelo homem moderno, freqüentemente em fragmentos, como tijolos, vidro, concreto, asfalto, pregos, plástico, metais diversos, pedra britada, cinzas e outros, provenientes, por exemplo, de detritos de demolição de edifícios.

2- Materiais "gárbicos" (do inglês garbage): são depósitos de material detrítico com lixo orgânico, de origem humana e que, apesar de conterem artefatos em quantidades muito menores que a dos materiais úrbicos, são suficientemente ricos em matéria orgânica para geram metano em condições anaeróbicas.

3- Materiais "espólicos" (do inglês spoil): materiais escavados e redepositados por operações de terraplanagem em minas a céu aberto, rodovias ou outras obras civis. Incluiríamos aqui também os depósitos os depósitos de assoreamento induzidos pela erosão acelerada. Seja como for, os materiais contêm muito pouca quantidade de artefatos, sendo assim identificados pela

possuindo potencial risco, em função da presença de materiais biológicos capazes de causar infecções, produtos químicos perigosos, objetos perfurocortantes efetiva ou potencialmente contaminados e mesmo rejeitos radioativos, necessitando de cuidados específicos de acondicionamento, transporte, armazenamento, coleta e tratamento. (OMS apud ANDRADE, 1995, p.03); Rutala e Mayhall (1992) descreveram "resíduo hospitalar" como todo resíduo, biológico ou não biológico, descartado e sem intenção de uso posterior. "Resíduos médicos", materiais gerados como resultado de diagnóstico, tratamento ou imunização de seres humanos e animais, "resíduo infeccioso", porção do resíduo médico capaz de transmitir uma doença infecciosa, e "Resíduos de Serviço de Saúde - RSS, "resíduos resultantes das atividades exercidas por estabelecimento gerador" (NBR 12.807), como por exemplo, hospitais, clínicas, laboratórios clínicos, ambulatórios, clínicas veterinárias etc.

9 "O conceito de depósito tecnogênico expressa a dinâmica morfogenética ao longo de um tempo - ainda que nesse caso a dimensão de tempo seja de menos escala (história humana); apresenta elementos de superação à medida que o conceito de depósitos correlativos não incluía os artefatos humanos em suas análises - resultando daí a concepção clássica do processo geomorfológico - como processo exclusivamente natural. Os depósitos tecnogênicos por sua vez permitem a incorporação, na dinâmica de formação desses depósitos, dos artefatos humanos, ampliando por conseqüência o conceito de processo geomorfológico ao introduzir o antropogênico" (SUERTEGARAY, 2002, p. 52). 
expressão geomórfica "não natural", ou ainda por peculiaridades texturais e estruturais em seu perfil.

4- Materiais "dragados": materiais terrosos provenientes da dragagem de cursos d'água e comumente depositados em diques em cotas topográficas superiores às da planície aluvial. (PEDOLOGIA, 1998, p. 74)

Por meio de estudos geomorfológicos é possível mensurar a ação humana, a qual influencia nas novas coberturas pedológias, formações geológicas, modificando assim, a paisagem.

\section{CARACTERIZAÇÃO DO SÍTIO URBANO}

O Município de Tupã (MAPA 01) foi fundado em 12 de outubro de 1929, por Luiz de Souza Leão, faz divisa com os Municípios de Arco-Irís, Herculândia, Quintana, Quatá, Bastos, João Ramalho e lacri.

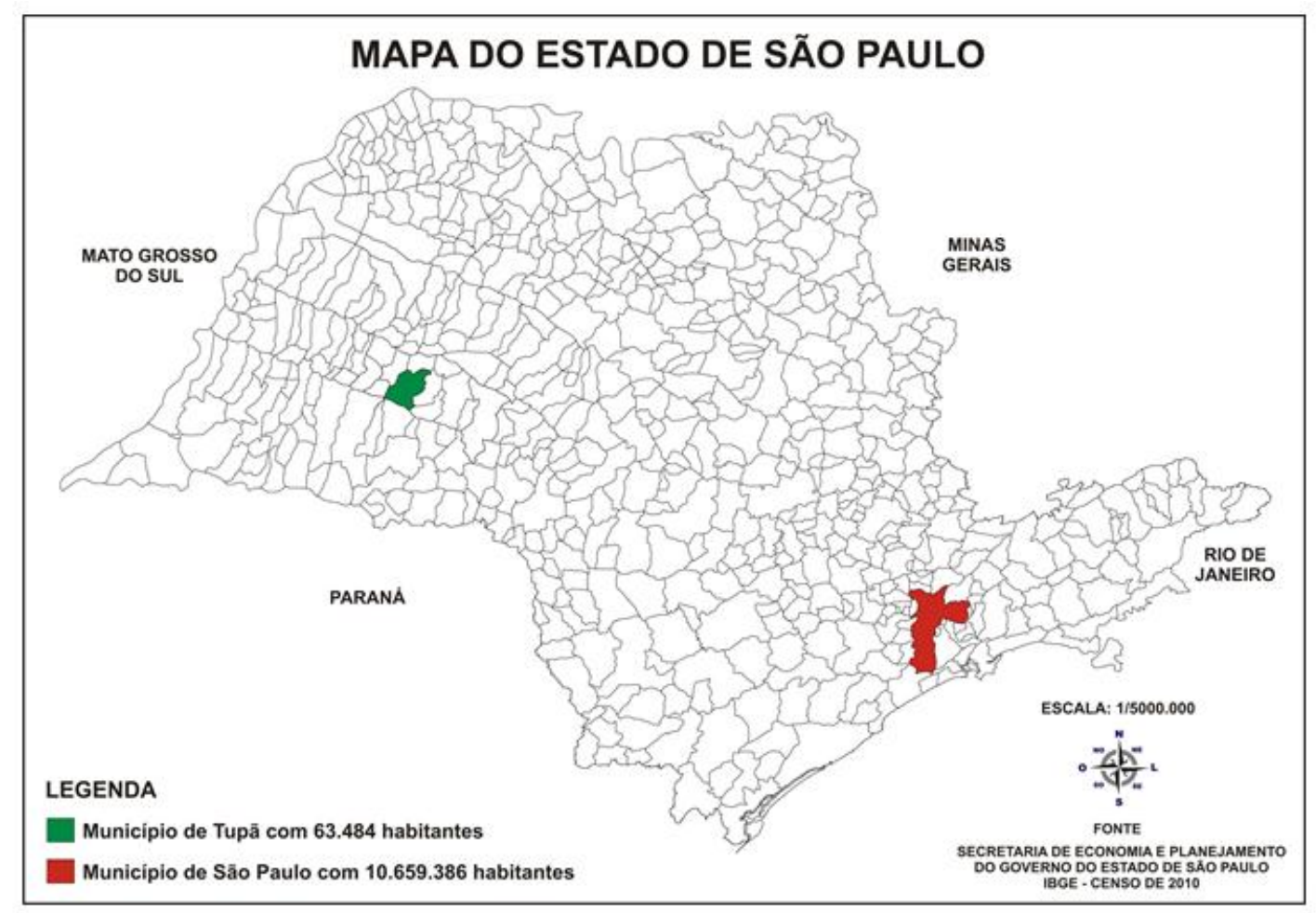

MAPA 01 - LOCALIZAÇÃO DO MUNICÍPIO DE TUPÃ 


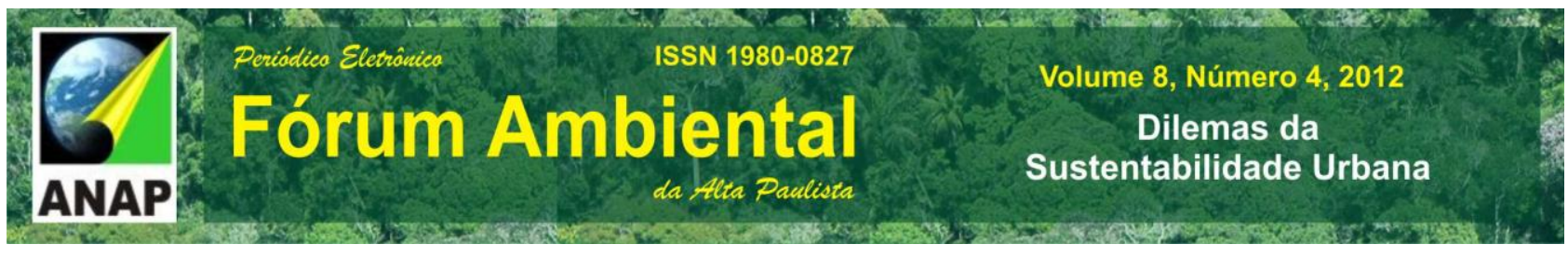

Os limites territoriais do Município de Tupã perfazem uma área de 629.108 m2, que abrange os Distritos de Varpa com 61.000 m2, Distrito de Universo com 114.000 m2, Distrito de Parnaso com 56.285,65 m2 e a cidade de Tupã com $33.643 \mathrm{~m} 2$. Segundo o Censo 2010 do IBGE, a população em 2010 era de 63.476 habitantes, sendo que 59.470 vivem na cidade, ou seja, na sede do município.

Como a maioria das cidades do Estado de São Paulo, Tupã adotou em seu plano inicial o tabuleiro de xadrez como proposto de arranjo espacial, o que permitiu a sua expansão urbana sem provocar alterações significativas no plano inicial. Entretanto, logo após a fundação da cidade em 1929, deu-se início ao processo de especulação imobiliária frente à ausência de instrumentos urbanísticos, a exemplo da Lei de Parcelamento do Solo (Lei Federal no 6766) que só foi decretada em 1979.

A figura 01 que trás o mapa da evolução urbana da cidade de Tupã mostra a expansão do sítio urbano numa escala temporal de 10 em 10 anos, onde é possível observar a ocupação dos fundos de vales.

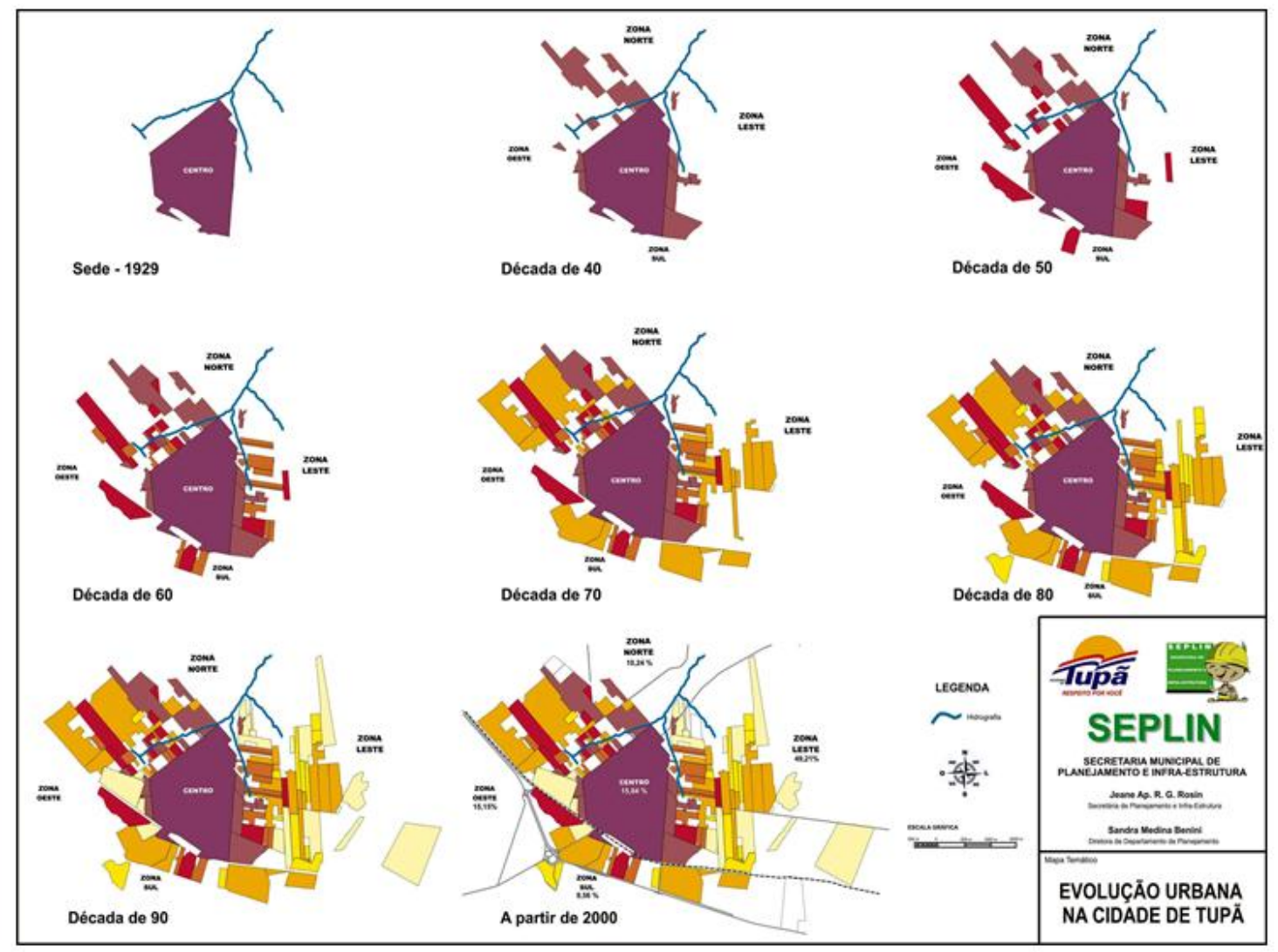

FIGURA 01 - Evolução Urbana da Cidade de Tupã

Fonte: SEPLIN, 2007.

VIII Fórum Ambiental da Alta Paulista, v. 8, n. 4, 2012, p. 43-63. 
As intervenções antrópicas na natureza resultam em impactos negativos que recaem sobre o meio ambiente. Com o processo de urbanização "os rios que corriam naturalmente, por exigência do crescimento urbano/demográfico", se tornaram "depósitos de lixo e locais de concentração da poluição com sólidos, insetos, odores etc" (CALLAI, 1993, p.53).

Os apontamentos de Callai (1993) refletem bem a realidade da cidade de Tupã, pois desde a fundação do sítio urbano até os dias atuais, os fundos de vales têm sido usados para destinação final de resíduos sólidos urbanos, se tornando locais de grande degradação e de depósitos tecnogênicos.

Segundo Peloggia (1998), depósitos tecnogênicos são aqueles resultantes da atividade humana, abrangendo depósitos construídos (aterros, corpos de rejeitos, etc.), depósitos induzidos, como os sedimentos que se depositam em razão da erosão decorrente do uso do solo e depósitos modificados (depósitos naturais alterados tecnogenicamente por efluentes, adubos, etc.).

Os depósitos tecnogênicos são categorizados nos tipos construídos e tipos induzidos. Construídos, diretos ou imediatos, são aqueles que resultam diretamente da ação antrópica, ou seja, representam os "bota-foras", as barragens diversas, os cortes e aterros, os depósitos de resíduos sólidos, dentre outros; os induzidos, indiretos ou mediatos, são atribuídos à efetuação humana, resultando de atividades ligadas ao uso do solo, atividades agrossilvopastoris, atividades industriais, com alterações na cobertura vegetal, estimulando os processos erosivos, cujo resultado final é a produção de sedimentos (CASSETI, 2005).

O Mapa 02 a seguir, demonstra os locais utilizados para o descarte de diferentes tipos de resíduos sólidos na área urbana de Tupã. É possível observar a localização de lixões em áreas de nascente e em margens de cursos d’água, além de bota-foras e depósitos de entulho. 

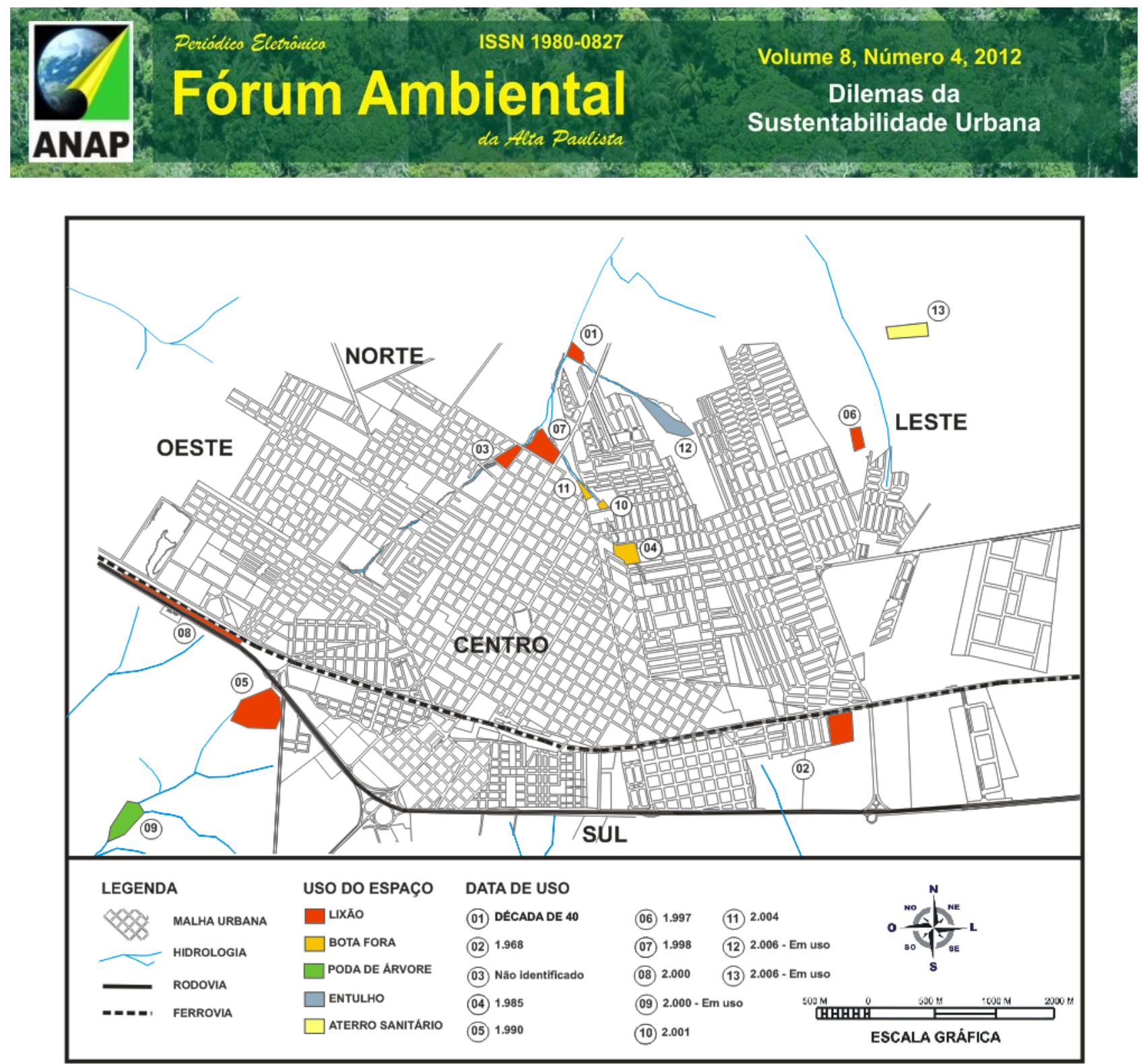

MAPA 02 - Histórico dos Depósitos Tecnogênicos na Cidade de Tupã

Fonte: Secretaria Municipal de Agricultura e Meio Ambiente; Secretaria Municipal de Planejamento e Infraestrutura; entrevista com funcionários públicos aposentados que realizavam a coleta de disposição dos resíduos e a comunidade das áreas identificadas (2006).

Organizado e Atualizado por Sandra Medina Benini, 2011.

Segundo Peloggia (1998, p.129), os depósitos apresentado no mapa temático (MAPA 2) podem ser classificados como “depósito 'úrbicos', predominantemente lançados em 'bota-fora', aterrando baixadas, fundos de vale [...] e em depósitos 'gárbicos', sejam tecnologicamente controlados (aterros sanitários) ou simples 'lixões'”. O mesmo autor (PELOGGIA, 1998) explica que estes espaços são

[...] caracterizados como uma matriz de solos lançados e solos superficiais remobilizados que engloba entulhos e artefatos diversos (madeira, restos de construção civil e demolições, restos de pavimentos, brita, ferro-velho) e lixo (sacos plásticos, restos de roupas, borracha, papel, matéria orgânicas). De 
constituição extremamente heterogênea, apresentam espessuras observadas elevadas, de menos de 1 metro até 7 metros, (como demonstrado por seções geológicas, levantadas com apoio de dados de investigações geotécnicas de subsuperfície, em diversos locais). (PELOGGIA, 1998, p. 76-77).

Considerando os apontamentos de Peloggia (1998), estes depósitos tecnogênicos contribuíram alteração da paisagem urbana, bem como, vêm provocando impactos ambientais negativos, a exemplo da poluição do solo, da água, do ar, a proliferação de vetores, etc.

\section{TUTELA AMBIENTAL}

Em matéria da autonomia ambiental, o Município de Tupã contempla um sistema normativo sobre a coleta de resíduos sólidos, originário da Lei № 42 de 25/09/1948, regulamentado posteriormente com a cobrança pela execução dos serviços instituída através do Código Tributário Municipal, Lei ํo 2.087/74.

Alguns anos depois, o Artigo 169, Inciso II, Lei no 3070, de 04 de abril de 1990, da Lei Orgânica ${ }^{10}$ do Município de Tupã, traçou as diretrizes para o manejo dos resíduos sólidos.

Artigo 169 - A lei estabelecerá a política das ações e obras de saneamento básico municipal, respeitando os seguintes princípios:

II - orientação técnica para os programas visando ao tratamento de despejos urbanos e industriais e de resíduos sólidos, fomento à implantação de soluções comuns, mediante planos regionais de ação integrada.

No que se refere à questão da coleta e transporte de resíduos da construção civil, a regulamentação foi efetivada pelas seguintes diplomas: Lei ํo 3.696/97, Lei oㅜ 3.717/97, Lei oㅜ 4.000/2002 e Lei ㄲo 4.139/2004. O Município de Tupã também detêm lei específica (Lei ํo 3.877/2000), que proíbe a queimada de mato, lixo, entulho e demais detritos em terrenos baldios.

Desde outubro de 2004, todo resíduo sólido urbano coletado é encaminhado para o aterro sanitário", onde o "tratamento primário do aterro consiste na aplicação de

\footnotetext{
${ }^{10}$ A Lei Orgânica se constitui como a célula mãe do sistema jurídico municipal, traçando regras diretrizes para organização do governo local, regendo a harmonia entre os poderes Executivo e Legislativo.

${ }^{11} \mathrm{O}$ aterro sanitário da Estância Turística foi inaugurado em outubro de 2004, na Gestão do Prefeito Manual Gaspar, localizado na Estrada TUP 496, s/nº, Bairro São Gonçalo.
} 
controles físicos que não alteram as características químicas e biológicas dos resíduos e dos contaminantes existentes no local" (ALBERTE, 2005).

Em 11 de fevereiro de 2008, por força da Lei Federal no 11.445, de 05/01/2007, a Câmara Municipal de Tupã, aprovou o Plano Municipal de Saneamento Básico de Limpeza Urbana e Manejo de Resíduos Sólidos Urbanos do Município de Tupã (Lei № 4.345), a qual estabelece os seguintes princípios:

\footnotetext{
Art. 2ํ Para o estabelecimento do Plano Municipal de Saneamento Básico de Limpeza Urbana e Manejo de Resíduos Sólidos Urbanos do Município de Tupã serão observados os seguintes princípios fundamentais: (NR)

I - a prevalência do interesse público;

II - a melhoria contínua da qualidade ambiental;

III - o combate à miséria e seus efeitos, que prejudicam não apenas a qualidade de vida, mas também a qualidade ambiental da cidade e de seus recursos naturais;

IV - a multidisciplinariedade no trato das questões ambientais;

$\mathrm{V}$ - a participação comunitária na defesa do Meio Ambiente

VI - a integração com as políticas de Meio Ambiente nas esferas de competência da União, Estado, Município e as demais ações do governo;

VII - manutenção de equilíbrio ambiental;

VIII - o uso racional dos recursos naturais;

IX - a mitigação e minimização dos impactos ambientais;

$X$ - a Educação e a Conscientização Ambiental como ação mobilizadora da sociedade;

$X I$ - o incentivo a pesquisa científica e tecnológica direcionada para o uso, proteção, monitoramento e recuperação dos recursos ambientais;

XII - o estímulo à produção responsável;

XIII - a recuperação do dano ambiental;

XIV - a melhoria contínua da qualidade da saúde pública.
}

Tais princípios têm a função de nortear o administrador público durante 0 processo de planejamento e gestão ambiental dos resíduos sólidos urbanos da Estância Turística de Tupã.

\section{PANORAMA ATUAL DA GESTÃO DOS RESÍDUOS SÓLIDOS URBANOS NA ESTÂNCIA TURÍSTICA DE TUPÃ}

Segundo o relatório do Plano Municipal de Saneamento Básico de Limpeza Urbana e Manejo de Resíduos Sólidos Urbanos do Município de Tupã, a municipalidade por meio da Secretaria Municipal de Meio Ambiente vem desenvolvendo uma "Gestão Ambiental Integrada dos Resíduos Sólidos Urbanos", a qual tem subsidiado ações de 
coleta, tratamento e disposição corretos dos resíduos sólidos urbanos na Estância Turística de Tupã. O Quadro 03 apresenta os serviços necessários para a gestão dos resíduos, a descrição e a responsabilidade por cada um.

QUADRO 03 - Gestão dos Resíduos Sólidos Urbanos na Estância Turística de Tupã

\begin{tabular}{|c|c|c|}
\hline SERVIÇOS & DESCRIÇÃO & RESPONSÁVEL \\
\hline \multirow{4}{*}{$\begin{array}{l}\text { Coleta e } \\
\text { Transporte }\end{array}$} & $\begin{array}{c}\text { Coleta e transporte de resíduos sólidos dos Serviços } \\
\text { Complementares. }\end{array}$ & Terceirizado \\
\hline & $\begin{array}{l}\text { Coleta e transporte de resíduos sólidos dos serviços } \\
\text { de saúde }\end{array}$ & Terceirizado \\
\hline & Coleta e transporte de resíduos sólidos domiciliares & Terceirizado \\
\hline & Coleta seletiva de recicláveis & $\begin{array}{c}\text { Secretaria de Agricultura e Meio } \\
\text { Ambiente }\end{array}$ \\
\hline \multirow{3}{*}{ Tratamentos } & Usina de triagem de recicláveis & $\begin{array}{l}\text { Cooperativa de Trabalho dos } \\
\text { Recicladores de Tupã - COORETUP }\end{array}$ \\
\hline & Usina de resíduos da construção civil. & $\begin{array}{l}\text { Secretaria de Agricultura e Meio } \\
\text { Ambiente }\end{array}$ \\
\hline & $\begin{array}{l}\text { Tratamento dos resíduos dos serviços de saúde - } \\
\text { (Realizado através do sistema de Autoclave) }\end{array}$ & Terceirizado \\
\hline \multirow{4}{*}{$\begin{array}{l}\text { Disposição } \\
\text { Final }\end{array}$} & $\begin{array}{l}\text { Aterramento dos resíduos dos serviços de saúde pós } \\
\text { tratamento e esterilização }\end{array}$ & Terceirizado \\
\hline & Aterro sanitário - (resíduos sólidos). & Terceirizado \\
\hline & Aterro de resíduos inertes da construção civil. & $\begin{array}{c}\text { Secretaria de Agricultura e Meio } \\
\text { Ambiente }\end{array}$ \\
\hline & Aterro de resíduos vegetais. & $\begin{array}{l}\text { Secretaria de Agricultura e Meio } \\
\text { Ambiente }\end{array}$ \\
\hline
\end{tabular}

Fonte: Secretaria Municipal de Agricultura e Meio Ambiente e Secretaria Municipal da Saúde, 2012. Organizado por Sandra Medina Benini, 2012.

Segundo o Inventário Estadual de Resíduos Sólidos Domiciliares $(2011)^{12}$, o Município de Tupã obteve os seguintes valores de IQR (Índices de Qualidade de Aterro de Resíduos) nos últimos anos: 2005 - 10,0; 2007 - 9,9; 2008 - 9,6; 2009 - 7,8 e 2010 - 8,8. Este índice foi definido de acordo com uma pontuação que varia de 0 a 10, obtida da consideração de 41 variáveis que abrangem três aspectos básicos: localização, infraestrutura e condições operacionais, permitindo o enquadramento dos sistemas analisados em três condições (Tabela 3):

${ }^{12}$ Disponível em: <http://www.cetesb.sp.gov.br/noticia/379,Noticia> Acesso em 01.11.2012. 


\section{TABELA 03 - IQR}

IQR / PONTUAÇÃO

$$
\begin{gathered}
0,0<\mathrm{IQR}<6,0 \\
6,1<\mathrm{IQR}<8,0 \\
8,1<\mathrm{IQR}<10,00
\end{gathered}
$$

\section{ENQUADRAMENTO}

Condições Inadequadas

Condições Controladas

Condições Adequadas

\begin{tabular}{|c|c|c|c|c|c|c|c|c|c|c|c|c|c|c|}
\hline \multirow[b]{2}{*}{ MUNICÍPIO } & \multicolumn{13}{|c|}{ INVENTÁRIO DE RESÍDUOS SÓLIDOS } & \multirow{3}{*}{$\begin{array}{l}\text { LIXO } \\
\text { (t/dia) }\end{array}$} \\
\hline & 1997 & 1998 & 1999 & 2000 & 2001 & 2002 & 2003 & 2004 & 2005 & 2007 & 2009 & 2010 & 2011 & \\
\hline DE & IQR & IQR & IQR & IQR & IQR & IQR & IQR & IQR & IQR & IQR & IQR & IQR & IQR & \\
\hline TUPÃ & 2,7 & 3,1 & 3,9 & 6,4 & 5 & 8,1 & 8,5 & 10 & 10 & 9,9 & 7,8 & 8,8 & 9,2 & 24,4 \\
\hline
\end{tabular}

No Quadro 1 a seguir são apresentados os valores de IQR para o município de Tupã, desde a criação do referido índice.

Quadro 1 - Valores de IQR de Tupã desde 1997.

Fonte: Relatório de Qualidade Ambiental - Estado de São Paulo, 2006 e Inventário Estadual de Resíduos Sólidos Domiciliares, 2011.

Nas Fotos 1, 2, 3 e 4 pode-se visualizar aspectos do aterro sanitário de Tupã.

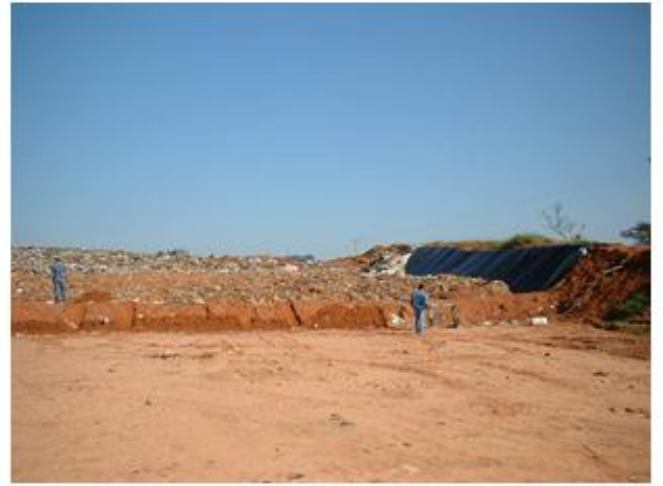

FOTO 01 - Aterro Sanitário - Célula impermeabilizada Data: 08.2005

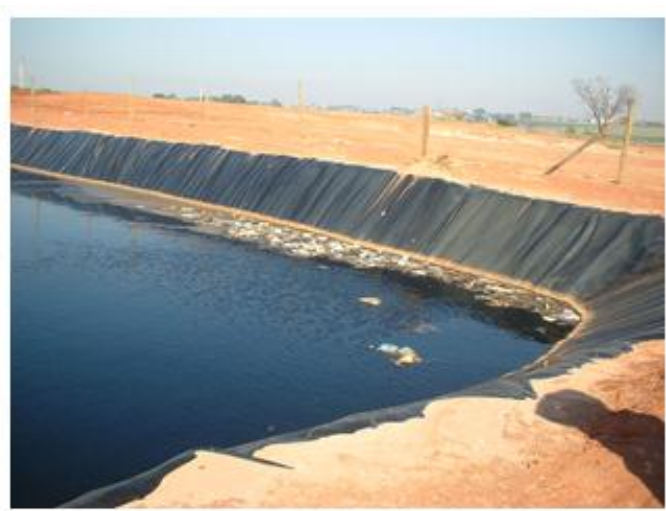

FOTO 02 - Aterro Sanitário - Lagoa impermeabilizada para tratamento de chorume Data: 08.2005 


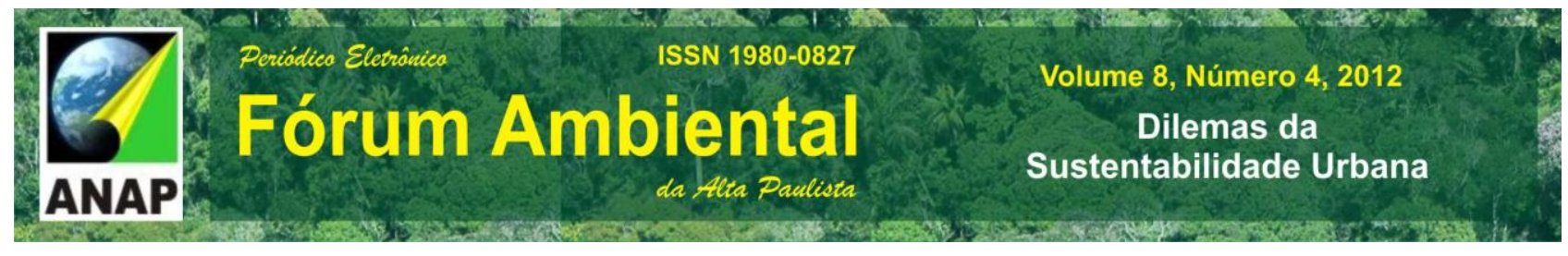

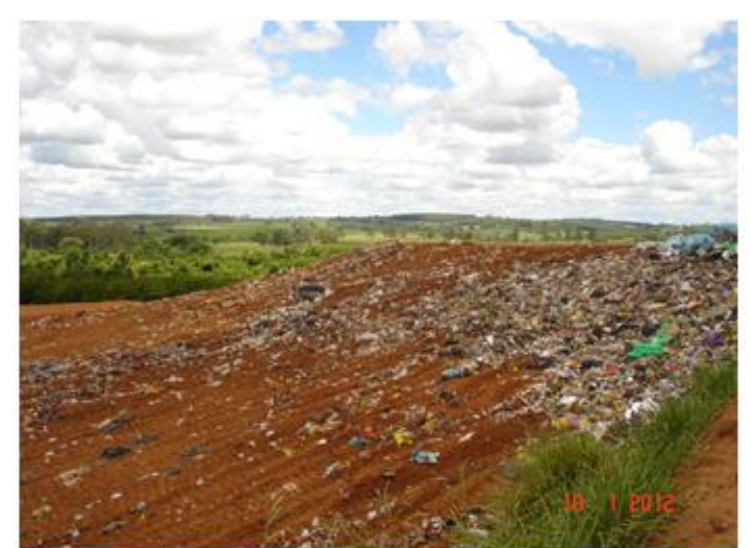

FOTO 03 - Aterro Sanitário

Data: 10.01 .2012 e cedida pela Secretaria Municipal de Meio Ambiente

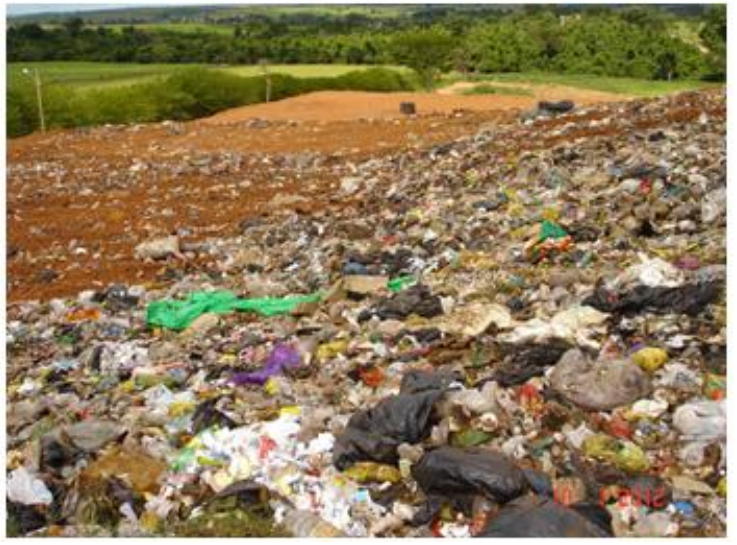

FOTO 04 - Aterro Sanitário

Data: 10.01 .2012 e cedida pela Secretaria Municipal de Meio Ambiente

Deve-se destacar que desde 23 de março de 2010, a coleta, tratamento e disposição dos resíduos sólidos foram terceirizados e passaram a ser responsabilidade da Empresa Leão Ambiental.

No tocante aos resíduos oriundos da construção civil, são regulados pela Resolução no 307/2002 ${ }^{13}$, que recomenda o tratamento do mesmo por meio de uma Usina de Reciclagem de Resíduos da Construção Civil.

Em Tupã, desde 2006, os resíduos da construção civil têm a disposição final no Aterro de Resíduos da Construção Civil, devidamente licenciado pela CETESB, com objetivo de aterrar uma voçoroca situada no Conjunto Habitacional Cônego Rebouças (FOTOS 5 e 6$)$.

\footnotetext{
${ }^{13}$ Aprovada pelo Conselho Nacional do Meio Ambiente em 2002, visa disciplinar as atividades relacionadas com os resíduos da construção civil, definindo o Plano Integrado de Gerenciamento de Resíduos da Construção Civil como um instrumento para superar um quadro constante de degradação, decorrente da sua inadequada gestão.
} 

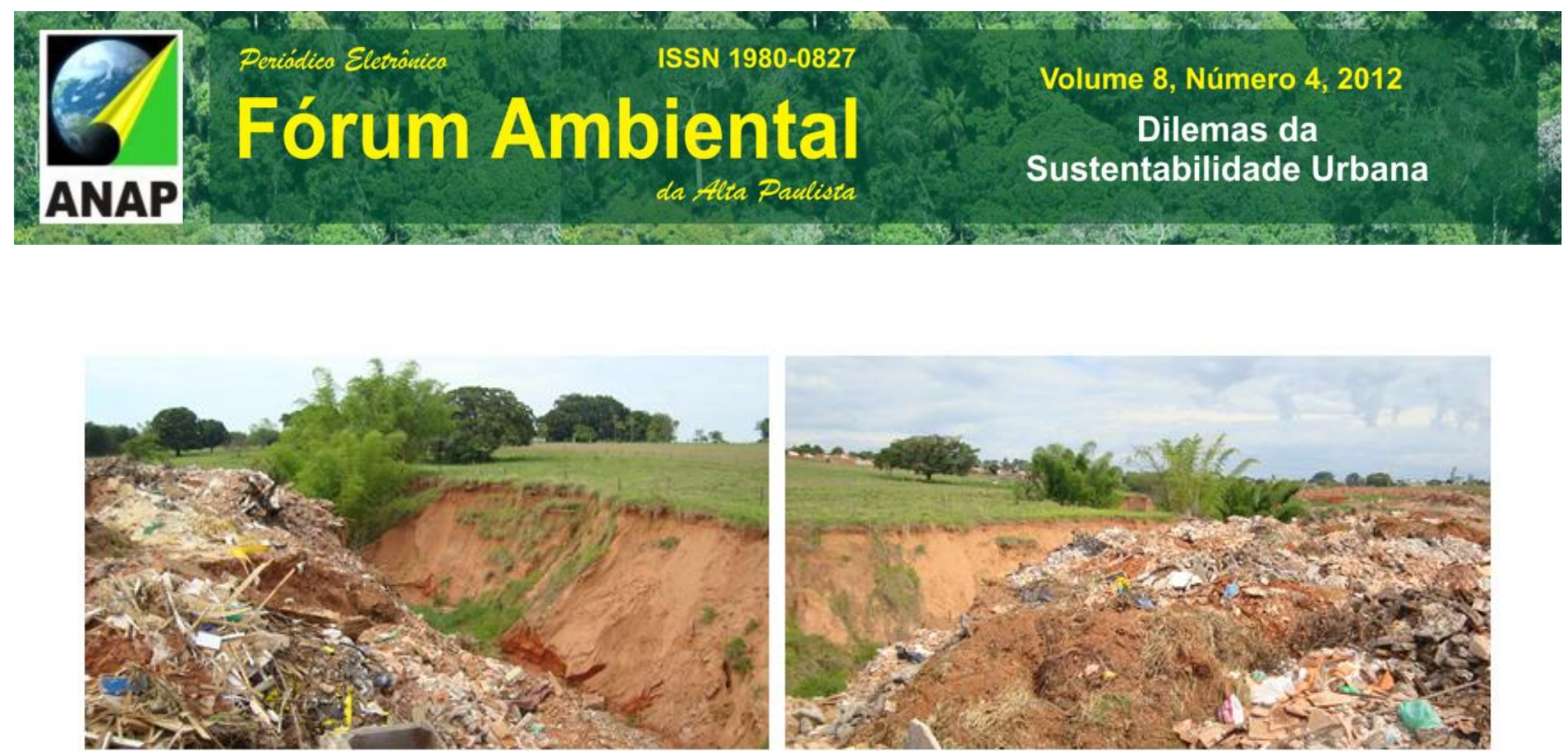

FOTOS 05 e 06 - Aterro de Resíduos da Construção Civil (Licenciado pela CETESB) Data: 06.11.2011

Em trabalho de campo realizado em novembro de 2011, foi verificado que o Aterro de Resíduos da Construção Civil recebia, tanto resíduos oriundos da construção civil, como resíduos provenientes dos cemitérios municipais (vasos de flores e entulho de material utilizado na construção das sepulturas), descartes de resíduos industriais (retalhos de lixas, plásticos, madeiram, tecidos, dentre outros) e domiciliares.

Recentemente, em 18 de maio de 2012, foi inaugurada a Usina de Reciclagem de Entulhos (FOTOS 07 e 08), situada no bairro São Gonçalo, próximo ao Aterro Sanitário. Segundo a Secretaria do Meio Ambiente, a obra contou com investimentos da ordem de $\mathrm{R} \$ 350$ mil, viabilizados junto ao Fundo Estadual de Prevenção de Controle de Poluição (FECOP) e teve de contrapartida R $\$ 43$ mil da Prefeitura Municipal.
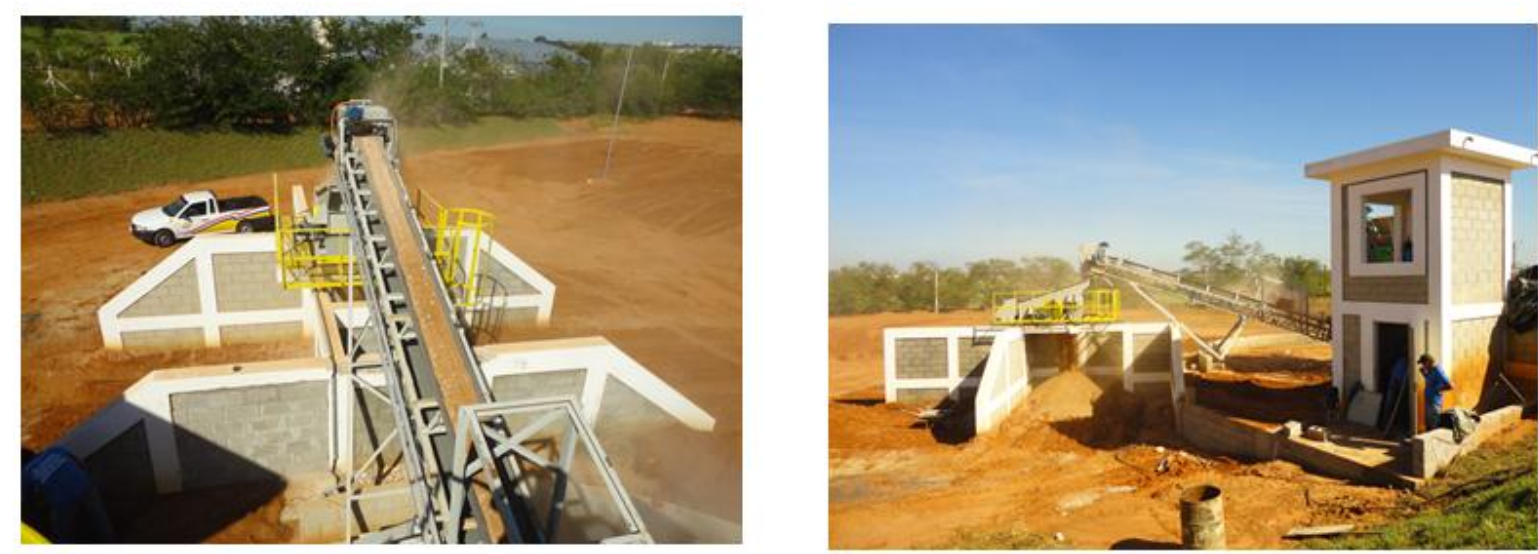

FOTOS 07 e 08 - Usina de Reciclagem de Resíduos da Construção Civil

Data: 24.04.2012 e cedidas pela Secretaria Municipal de Meio Ambiente 


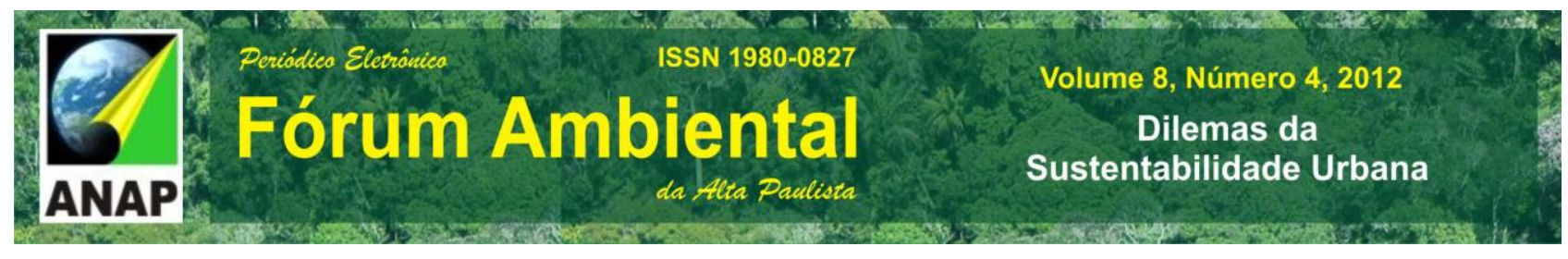

Apesar da Usina de Reciclagem de Entulhos apresentar uma capacidade de trituração de 40 caçambas diárias com capacidade para $3 \mathrm{~m}^{3}$, esta funciona esporadicamente, somente para triturar materiais que são utilizados na manutenção de estradas rurais.

No que se referem aos resíduos vegetais (originados nas atividades de poda e capina), estes são destinados ao Aterro de Resíduos Vegetais (conhecido como Aterro do Piva), situado na Estância Piva, na Estrada do Picadão. O local não é licenciado pela CETESB e tem por finalidade o aterramento de uma voçoroca.

Em 2005, o Governo Municipal, por meio da Secretaria do Meio Ambiente, ao executar o Projeto "Cidade Limpa", numa parceria promocional com a Rede Globo, destinou todos os materiais recolhidos na cidade, para o Aterro de Resíduos Vegetais (FOTOS 09 e 10).

As fotos (09 e 10) demonstram o descaso e ausência de compromisso com a questão ambiental. Em 2011, o local estava completamente aterrado (FOTOS 11 e 12), em alguns lugares havia focos de queimada de resíduos vegetais, bem como, materiais diversos, como pneus usados e sacos plásticos.
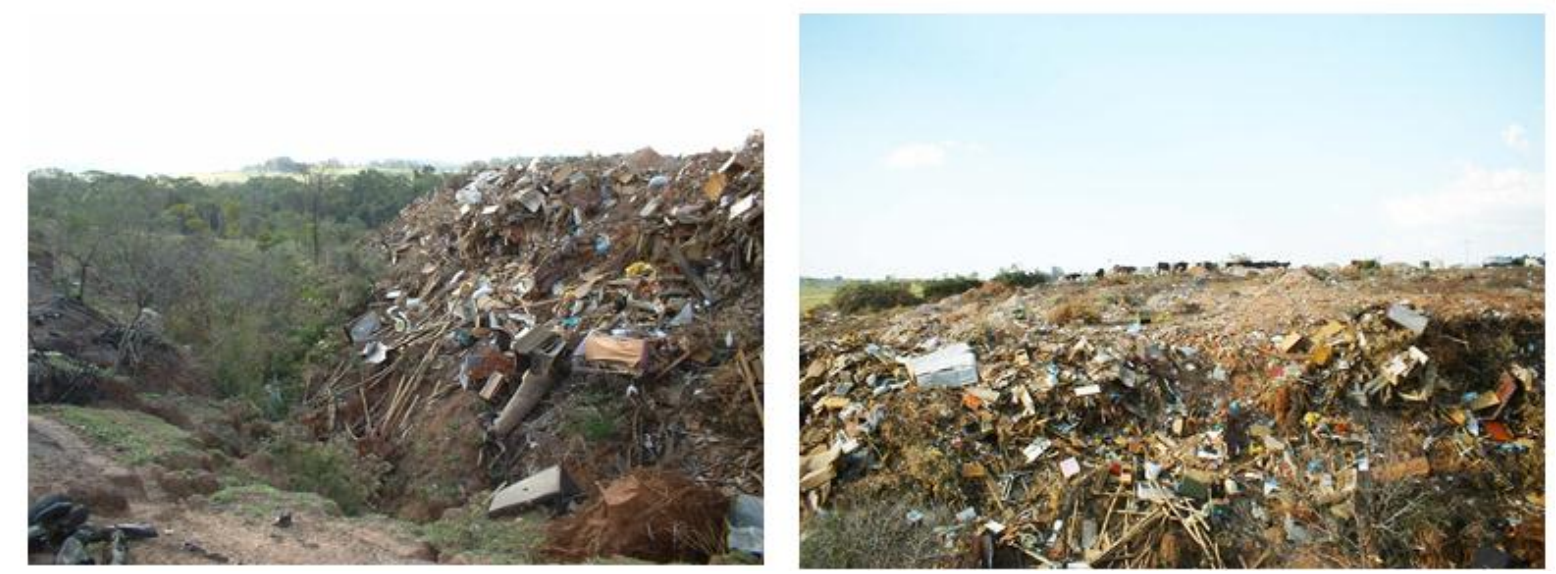

Aterro de Resíduos Vegetais

Exclusivo para Galho e Terra, após a execução do Projeto "Cidade Limpa" FOTOS 09 e 10 - Aterro de Resíduos Vegetais - Exclusivo para Galho e Terra Data: 2005 

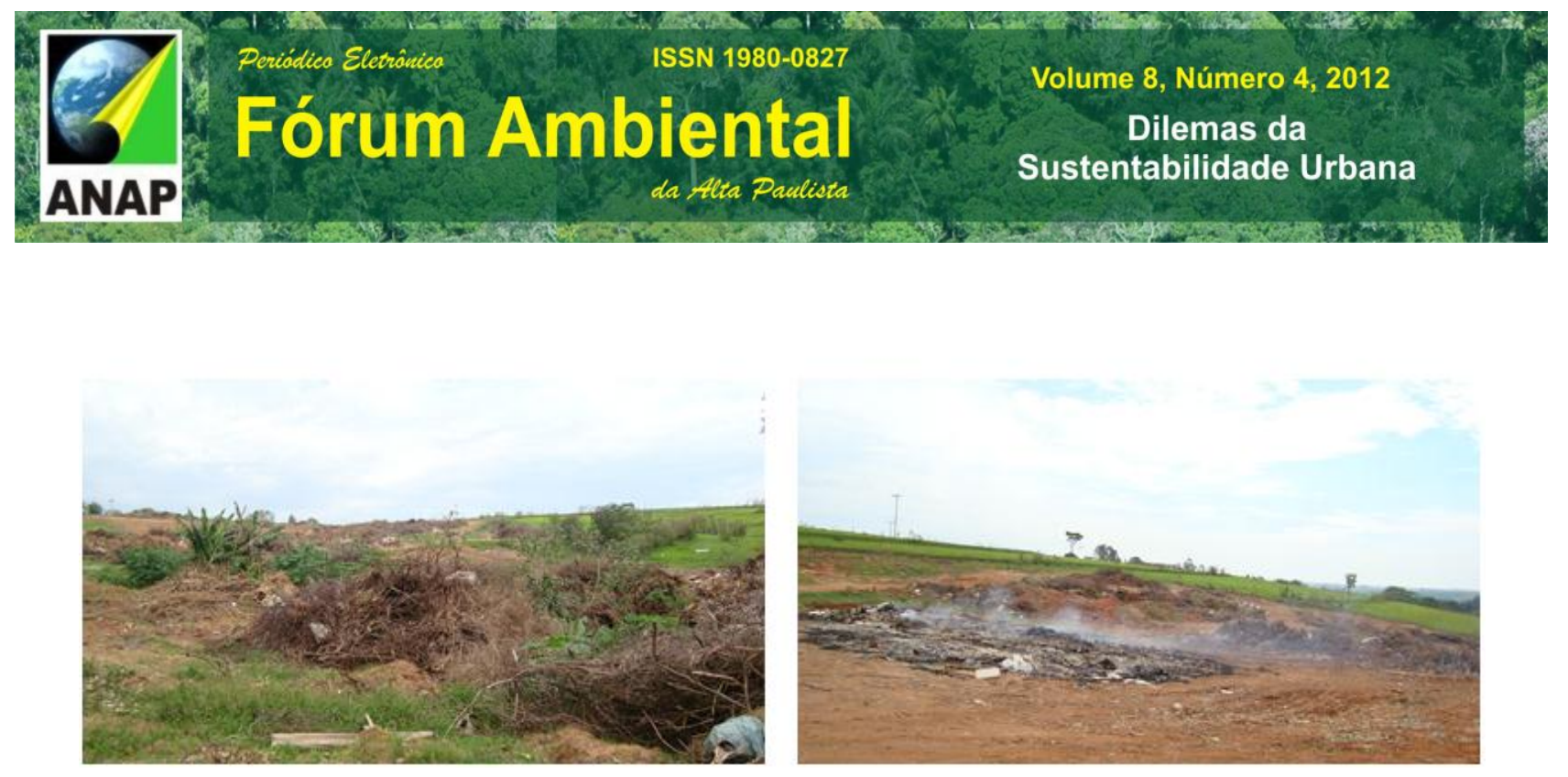

FOTOS 11 e 12 - Aterro de Resíduos Vegetais - Exclusivo para Galho e Terra Data: 06.11.2011

Já a coleta, disposição final dos resíduos sólidos provenientes dos serviços de saúde são terceirizados, para as empresas Sterlix Ambiental (responsável pela coleta e transporte do resíduo, esterilização e destinação final). Segundos dados da Secretaria Municipal da Saúde (2012), no Município são coletados aproximadamente $1.300 \mathrm{~kg} / \mathrm{mês}$ oriundos dos hospitais, Posto de Saúde da Família, clínicas odontológicas, laboratórios, estabelecimentos farmacêuticos e clínica veterinárias. Hospitais celebram contrato particular.

Desde outubro de 2001 está implantado no município, o projeto de coleta seletiva, denominado "Reciclar é Legal", que era desenvolvido em parceria com ASTURE Associação Comunitária Tupãense de Reciclagem ${ }^{14}$. A coleta seletiva é realizada na cidade de Tupã e nos Distritos. O projeto representa um avanço em gestão ambiental, uma vez que a coleta e reciclagem de resíduos sólidos são alguns dos melhores exemplos de desenvolvimento sustentável, sendo possível conciliar as questões ambientais, econômicas e sociais num mesmo contexto.

Em Tupã a reciclagem dos resíduos domésticos é fonte de renda para várias famílias, apesar de existirem ainda, muitos catadores de resíduos que não tem vínculos associativos com a ASTURE e recolhem materiais recicláveis por conta própria. Essa situação ocasionou a formação de depósitos clandestinos de materiais recicláveis em áreas públicas da Prefeitura Municipal.

\footnotetext{
14 A Associação, assistida pela Administração Pública, foi constituída na ocasião, pelos catadores de material reciclável do Lixão Municipal, e é uma pessoa jurídica de direito privado, sem fim lucrativos.
} 
Em 08 de Dezembro de 2006, a ASTURE foi fechada e seus integrantes, sob orientação da Secretaria Municipal do Meio Ambiente, montaram a Cooperativa de Trabalho dos Recicladores de Tupã - COORETUP.

A cooperativa COORETUP recebe auxílio financeiro por força da Lei $n-4533$ (aprovada em 19 de abril de 2011), a qual autoriza o poder público a celebrar termos de convênio e aditamento, visando à operacionalização da Central de Reciclagem da COORETUP, para a triagem, prensagem, enfardamento e comercialização de materiais recicláveis.

\section{CONSIDERAÇÕES FINAIS}

A Estância Turística de Tupã apresenta uma estrutura complexa (jurídica e física) para realizar a Gestão Integrada dos Resíduos Sólidos Urbanos, colocando o Município de Tupã em vantagem frente à maioria dos demais municípios brasileiros.

Embora possua uma estrutura complexa e diferenciada em relação à maioria dos municípios brasileiros, ambientalmente a gestão dos resíduos ainda carece de melhorias, principalmente no tocante à disposição final dos mesmos. O que pode ser observado, é que maior dilema a ser vencido pelo Governo de Tupã para que haja uma gestão eficiente, é fazer com que as questões técnicas tenham papel mais relevante do que as políticas, para que possam vir a assegurar um meio ambiente sadio e equilibrado é essencial à qualidade de vida da população.

\section{REFERÊNCIAS}

ALBERTE, E. P. V. et. al. Recuperação de Áreas Degradadas por Disposição de Resíduos Sólidos Urbanos. In: Diálogos \& Ciência, Revista Eletrônica da Faculdade de Tecnologia e Ciências de Feira de Santana. Ano III, n. 5, jun. 2005.

ANDRADE, J. B. L. Análise do fluxo e das características físicas, químicas e microbiológicas dos resíduos de serviços de saúde: proposta de metodologia para 0 
gerenciamento em unidade hospitalares. São Carlos. Tese (doutorado) - Escola de Engenharia de São Carlos, Universidade de São Paulo, 1997.

ASSOCIAÇÃO BRASILEIRA DE NORMAS TÉCNICAS. NBR 10.004 - Resíduos sólidos: classificação. São Paulo, 2004.

BOIN, Marcos Norberto. Chuvas e erosões no oeste paulista: Uma análise climatológica aplicada. Tese (Doutorado) Curso de Pós- Graduação em Geociências - Área de Concentração em Geociências e Meio Ambiente, Rio Claro. 269p., 2.000.

CALDERONI, Sabetai. Os bilhões perdidos no lixo. 4 ed. São Paulo: Humanistas Editora / FFLCH / USP, 2003.

CALLAI, H. C. A Cidade e a (re)criação da relação homem-natureza. Revista Ciência \& Ambiente, 1993, p. 43-53.

CASSETI, Valter. Geomorfologia. [S.I.]: [2005].

CICOTTO, M. A. Utilização de subprodutos e resíduos na indústria da construção civil. In: Tecnologia de edificações. 1. ed. Coletânea de trabalhos. PINI/IPT: São Paulo, 1998.

CHRISTOFOLETTI. Geomorfologia. 2ª ed. São Paulo: Edgar Blucher, 1980.

GRIPPI, Sidney. Lixo, reciclagem e sua história: Guia para as prefeituras brasileiras. Rio de Janeiro: Interciênia, 2001.

HARDUEL, Jean-Louis. O urbanismo da era industrial. In: História do urbanismo. Campinas: Papirus, 1990. p. 101-148.

HOBSBAWM, E. A era dos extremos: o breve século XX: 1914-1991. São Paulo:

Companhia das Letras, 1995.

LIMA, J. D. de. Gestão de Resíduos Sólidos Urbanos no Brasil. RESOL Engenharia Ltda / ABES - Associação Brasileira de Engenharia e Ambiental, 2001.

LOPES, A. A. Estudo da gestão e do gerenciamento integrado dos resíduos sólidos urbanos da cidade de São Carlos. Dissertação (Mestrado) - Ciências da Engenharia Ambiental, pela Escola de Engenharia de São Carlos da Universidade de São Paulo, 2003.

LÜDKE, M.; ANDRÉ, M. E. D. A. Pesquisa em educação: abordagens qualitativas. São Paulo: EPU, 1986.

MACHADO, P. J. O. Uma proposta de zoneamento ambiental para a bacia hidrográfica da represa de São Pedro Juiz de Fora - MG. Presidente Prudente, 1998. Dissertação (Mestrado em Geografia na Unesp de Presidente Prudente)

MAGALHÃES JR., Antonio. Variáveis e desafios do processo decisório no contexto dos comitês de Bacias hidrográficos no Brasil. In. Ambiente \& Sociedade. Campinas, SP: UNICAMP, Ano IV, n. 8, 1. semestre de 2001, p. 21-48. 
MAZZETO, F. A. P. Qualidade de vida, qualidade ambiental e meio ambiente urbano: breve comparação de conceitos. In: Sociedade \& Natureza (Revista do Instituto de Geografia da UFU). Uberlândia: EDUFU, 2000, Ano 12, n.24, p. 21-31.

PELOGGIA, A. O homem e o ambiente geológico: geologia, sociedade e ocupação urbana no município de São Paulo. São Paulo: Xamã, 1998.

PHILIPPI JR., A..; AGUIAR, A. O.. Resíduos sólidos: características e gerenciamento. In: PHILIPPI JR., A.. (ed.) Saneamento, saúde e ambiente: Fundamentos para o desenvolvimento sustentável. Barueri, SP: Manole, 2005.

RUTALA W. A., MAYHALL, C. G. Medical waste. Infection Control and Hospital Epidemiology, v.13, n.1, p.38-48. 1992.SECRETARIA DE ASSISTÊNCIA À SAÚDE. Manual Brasileiro de Acreditação Hospitalar .- Brasília: Ministério da Saúde, 3 ed, ver. e atual. 2002. p. 102 e 103.

SÃO PAULO. Relatório de Qualidade Ambiental - Estado de São Paulo, 2006.

SEWELL, G.H. Administração e controle da qualidade ambiental. São Paulo: USP, 1978, 295p.

SAULE JÚNIOR, Nelson. Estatuto da Cidade: Instrumento de reforma Urbana. [on-line] Disponível em <http://www.estatutodacidade.org.br/estatuto/artigos.shtml>. Acesso em 20 de abril de 2005.

SPOSITO, Maria Encarnação B. Capitalismo e Urbanização. 14. ed. São Paulo: Contexto, 2004.

SUERTEGARAY, D. M. A. Geografia física e Geomorfologia: Uma [Re] Leitura. ljuí: Ed. Unijuí, 2002.

VIANNA, José Ricardo Alvarez. Responsabilidade Civil por Dano ao Meio Ambiente. Curitiba: Juruá, 2004, p. 22. 